This item was submitted to Loughborough's Research Repository by the author.

Items in Figshare are protected by copyright, with all rights reserved, unless otherwise indicated.

\title{
The influence of the physical education environment on children's well-being and physical activity across the transition from primary to secondary school
}

\section{PLEASE CITE THE PUBLISHED VERSION}

http://dx.doi.org/10.1123/jsep.2014-0038

\section{PUBLISHER}

(c) Human Kinetics Journals

\section{VERSION}

AM (Accepted Manuscript)

\section{PUBLISHER STATEMENT}

This work is made available according to the conditions of the Creative Commons Attribution-NonCommercialNoDerivatives 4.0 International (CC BY-NC-ND 4.0) licence. Full details of this licence are available at: https://creativecommons.org/licenses/by-nc-nd/4.0/

\section{LICENCE}

CC BY-NC-ND 4.0

\section{REPOSITORY RECORD}

Taylor, lan, Christopher Spray, and Natalie Pearson. 2014. "The Influence of the Physical Education Environment on Children's Well-being and Physical Activity Across the Transition from Primary to Secondary School". Loughborough University. https://hdl.handle.net/2134/17141. 
2 Running head: PHYSICAL EDUCATION DURING SCHOOL TRANSITION

3

4

5

6

7

8

9 The influence of the physical education environment on children's well-being and physical activity across the primary-secondary school transition

11

12

13 Manuscript submitted: February $14^{\text {th }}, 2014$

14 Manuscript resubmitted: June $9^{\text {th }}, 2014$

15 Manuscript $2^{\text {nd }}$ resubmission: August 5th, 2014

16

17

Author Note: This study was supported by a grant from the Nuffield Foundation

18

(SGS/39228) awarded to the first and second authors.

19

20

21

22

23

24

25 
Abstract

27 The purpose of the study was to explore change in children's physical self-concept and self-

28 reported physical activity over a school transition period, as well as motivational and

29 interpersonal influences on these two outcomes. Data were collected from 545 children

30 (Mean age $=10.82, S D=0.39,51 \%$ female) at three time points before and after the United

31 Kingdom secondary school transition. Multilevel modeling revealed that physical selfconcept and physical activity showed different patterns of decline over the course of the study. Changes in the extent to which physical education (PE) teachers were perceived to provide psychological need support, peer focus on self-referenced learning and mastery, and changes in autonomous motives towards PE classes were positively associated with these outcome variables. The present study provides novel insight into important motivational and interpersonal factors that may need to be targeted to prevent negative developmental patterns over a potentially challenging period for children. 
The influence of the physical education environment on children's well-being and physical activity across the primary-secondary school transition to accrue physical and mental health benefits (e.g., Verloigne et al., 2012). If current trends continue, it is proposed that there will be a significant burden on the health services of the developed world as today’s inactive youth progress through the life course (British Heart Foundation, 2009). Schools have been recognized as key contexts, not only for promoting physical activity and healthy lifestyles, but for helping young people to realize their potential and feel good about themselves (Centers for Disease Control \& Prevention, 2011). There is, therefore, a strong case to investigate motivational phenomena within structured school settings with a view to understanding children's well-being and physical activity. The physical education (PE) ‘classroom’ provides a unique environment for investigating motivational and developmental issues among all young people. Because children participate in PE lessons throughout their school careers, it has been argued that PE can contribute to the development of positive physical self-perceptions, self-esteem, and physical activity in and beyond the school setting (Fox, 1992). During the compulsory school years, however, individuals typically transfer to a new school on two or three occasions (e.g., elementary to junior high in the United States and primary to secondary in the United Kingdom). Despite school transitions being associated with changes in perceptions of the self (Meece, Anderman, \& Anderman, 2006), there is a lack of understanding of the interpersonal and motivational factors that help to explain changes in physical self-concept and physical activity over this period. Moreover, distinguishing between shifts in self-concept and behavior over the transition period and more general linear changes is necessary. Physical self-concept refers to how individuals perceive and evaluate their physical self and includes feelings of "self-confidence, self-worth, self-acceptance, competence, and 
ability” (Marsh, 2007, p.160). Studies have shown that a positive physical self-concept, as well as representing a desirable developmental outcome in its own right, has important consequences for young people’s physical activity behavior (Crocker, Sabiston, Kowalski, McDonough, \& Kowalski, 2006) and may contribute to adolescents’ global self-esteem (Marsh, 2007). However, school transitions represent periods whereby young people encounter new environments, and significant individual and social developmental changes occur (Wigfield, Eccles, \& Pintrich, 1996). In addition, declines in motivation and selfbeliefs often seen at the time of transition may be a consequence of the mismatch between the needs of the individual and the school environment, and that many of the changes students encounter in the new school do not facilitate positive developmental outcomes (Meece et al., 2006). In contrast to transitional shifts, somewhat linear gradual processes may occur, whereby increasing cognitive maturity allows adolescents to adopt a more realistic judgment of their competencies in relation to others, which often leads to lower self-evaluations (Marsh, 1989).

Evidence also exists that physical activity shows overall declines during childhood and adolescence (Brodersen, Steptoe, Boniface, \& Wardle, 2007), despite some evidence to suggest that aspects of physical activity behavior (e.g., active travel and bicycling) may be unharmed (Garcia, Pender, Antonakos, \& Ronis, 1998) or increase somewhat over the transitional period (e.g., Cooper, Jago, Southward, \& Page, 2012). Indeed, it is these contrasting patterns that are a central focus of the present study as researchers have yet to consider that developmental trends and transitional shifts in self-concept and activity may occur simultaneously. This more accurate description and delineation of temporal patterns will enable researchers to implicate broader developmental processes or the change in schools as key influences on changing self-evaluations and behavior. 
Despite the numerous benefits of a physically active lifestyle for children and

adolescents (Stensel, Gorely, \& Biddle, 2008), little research has shed light onto the potential

101 developmental mechanisms during this important period. Research examining self-

102 perceptions has documented a decline in perceptions of competence in PE across the primary-

103 secondary school transition (Warburton \& Spray, 2008). There is, nevertheless, no evidence

104 pertaining to the motivational processes underpinning the development of physical selfconcept across the transition.

\section{Interpersonal Environment in Physical Education: The Role of Teachers and Peers}

Teaching practices within school settings represent a powerful developmental influence on students’ motivation and beliefs (Eccles \& Roeser, 2011). Using self-determination theory

109 (Deci \& Ryan, 2000), researchers have explored the extent to which teachers support students’ psychological needs by enhancing students' feelings of volition and self-governance (i.e., autonomy support; Cheon, Reeve, \& Moon, 2012), providing quality information on

112 how students can achieve desired outcomes (i.e., structure; Connell \& Wellborn, 1991), and

113 promoting feelings of belonging and connectedness (i.e., involvement; Connell \& Wellborn, 114 1991). Within the PE context, a body of largely cross-sectional research proposes positive 115 relationships between this 'psychological need support' and students' adaptive motivation, engagement, and psychological health (e.g., Taylor \& Ntoumanis, 2007), although more

117 consideration of structure and involvement has been entreated (Standage, Gillison,

118 Ntoumanis, \& Treasure, 2012).

Beyond the role played by teachers, children's peers have long been espoused as an

120 important developmental influence (e.g., Eccles \& Roeser, 2011), and may also have a

121 notable, yet different, impact on the PE class environment. For example, peers may not be

122 likely to play a major role in creating a well-structured class with expectations and

123 consequences clearly outlined; however, peers may significantly influence what aspects of 
124 achievement children focus on during tasks (Horn \& Amorose, 1998). Achievement goal 125 theory (Nicholls, 1989) differentiates between two types of motivational environment that

126 students’ peers may help to create. First, a task-involving climate encourages effort, task

127 mastery and improvement so that young people derive satisfaction from personal progress. In

128 contrast, an ego-involving climate fosters comparison with peers so that children derive

129 satisfaction from competing with and beating others, and demonstrating greater competence

130 than their peers with less observable effort. A dearth of research exists concerning the peer-

131 created motivational environment in PE, however, within youth sport contexts a peer-created

132 task-involving climate has been associated with more adaptive cognitive, affective and

133 behavioral outcomes, compared to an ego-involving climate (e.g., Jõesaar, Hein, \& Hagger,

134 2012; Ntoumanis, Taylor, \& Thøgersen-Ntoumani, 2012). There is a need to establish

135 temporal patterns in associations between peer-climate, self-beliefs, and physical activity as

136 they transfer schools and encountered different PE classes.

\section{Motivation in PE}

138 Self-determination theory has also been extensively employed to explore children's

139 motivation in school settings. The theory differentiates between types of motivation that vary

140 in their levels of self-determination. At the most self-determined, or autonomous, end of the

141 continuum is intrinsic motivation, which refers to the enactment of an activity for its own

142 sake, because the activity is interesting and enjoyable. Next are three types of extrinsic

143 motivation, which reflect engagement in an activity for reasons separate from the activity

144 itself. In a descending order of self-determination, the different motives are: Identified

145 regulation (i.e., pursuit of an activity to obtain desired and personally valued outcomes),

146 introjected regulation (i.e., engagement in behavior to feel worthy or to avoid feelings of guilt

147 or shame) and external regulation (i.e., engagement to obtain a reward or avoid punishment).

148 Finally, when a student perceives no worthwhile reason for taking part in PE, he or she is 
149 amotivated, that is, neither intrinsically nor extrinsically motivated (Deci \& Ryan, 2000). A 150 significant quantity of PE-based research (e.g., Standage, Duda, \& Ntoumanis, 2003; Taylor,

151 Ntoumanis, Standage, \& Spray, 2010) suggests that adaptive outcomes generally result from

152 intrinsic motivation and identified regulation. In contrast, maladaptive outcomes are generally

153 associated with controlling regulations (i.e., introjected regulation, external regulation and

154 amotivation, although this proposal has not always been observed regarding introjected 155 regulation (e.g., Gillison, Osborn, Standage, \& Skevington, 2009).

Although changes towards increasingly maladaptive motivational environments and

157 experiences have been observed across later childhood and adolescence (e.g., Barkoukis,

158 Ntoumanis, \& Thøgersen-Ntoumani, 2009; Ntoumanis, Barkoukis, \& Thøgersen-Ntoumani, 159 2009), linear changes across school transitions have only recently begun to be explored 160 (Spray, Warburton, \& Stebbings, 2013). However, it is possible that temporary increases in autonomous motivation may occur due to the novelty of joining a new school (cf. Delamont \& Galton, 1986) but this may mask more general declines over childhood. In addition, self-

163 determination theory and achievement goal theory can be used to understand the

164 interpersonal and motivational factors that help to explain and potentially off-set declining self-evaluations and changes in physical activity over the school transition.

\section{Aims and Hypotheses}

The present study sought to identify changes in the PE class environment, motivation

168 towards PE, physical self-concept and physical activity behavior across the primary-

169 secondary school transition by simultaneously exploring linear trends and transitional shifts.

170 We expected that students' physical self-concept would linearly decline on average, because

171 of increasing cognitive maturity (Marsh, 1989) rather than transitional changes. We also

172 expected physical activity and autonomous motivation to show a general linear decline to

173 reflect broad developmental processes (Brodersen et al., 2007; Ntoumanis et al., 2009) but 
174 also a positive transitional shift (i.e., an increase) from primary to secondary school (Cooper

175 et al., 2012; Delamont \& Galton, 1986). No linear changes were expected in introjected and

176 external regulation, whereas amotivation was expected to increase linearly (Ntoumanis et al.,

177 2009). A lack of previous longitudinal research across educational transitions prevented us

178 from speculating on transitional shifts in these variables, as well as any trends in the

179 interpersonal factors within PE.

180 We also aimed to investigate whether interpersonal and motivational factors could

181 explain the linear or transitional changes in physical self-concept and physical activity over

182 this period. On the basis of theory and prior research on relationships between achievement

183 goals, motivation and individuals’ beliefs and behavior (Taylor \& Ntoumanis, 2007;

184 Ntoumanis et al., 2012), we expected that perceived teacher needs support and peer task

185 climate across the transition would positively predict physical self-concept and physical

186 activity. In contrast, we expected the inverse relationship to be observed between a perceived

187 ego-climate and the outcomes under consideration. Regarding the motivational determinants,

188 we hypothesized that autonomous regulations (i.e., intrinsic and identified regulation) across

189 the transition would be positively associated with physical self-concept and physical activity,

190 whereas controlling regulations (i.e., introjected regulation and external regulation) and

191 amotivation would be negatively related to the outcomes.

\section{Method}

\section{Participants and Procedures}

The United Kingdom school system usually involves moving from primary school to secondary school at approximately 11-years-old, when students experience a complete change in school environment, including new peers and teachers and different class sizes.

197 Nine hundred and thirty-nine primary school children provided data at the first time point, 198 however, because we wanted to analyze linear and transitional change over time, participants 
199 who did not complete measures at all three time points were not included in the analysis.

200 Hence, 545 primary school students aged between 10 and 12 years-old $(M=10.82, S D=$

201 0.39, 51\% female) who were based in 52 classes taught by different teachers participated in

202 the study. These students were subsequently taught by 40 different PE teachers in secondary

203 school. Schools were based in Wales and the Midlands region of England. A series of

204 multivariate analysis of variance tests using Wilk’s lambda test statistic revealed no

205 differences in study variables across the participants with and without complete data, with the

206 exception of slightly lower self-reported physical activity in participants with complete data

207 (3.46 versus 3.60; $p<.05$; partial $\eta^{2}=0.1$ ). Attrition was mainly due to students transitioning

208 to a secondary school that was not part of the study or absence from school on the day of data

209 collection.

210 Following acceptance of an invitation to participate, consensual procedures

211 commensurate with the American Psychological Association regulations were conducted

212 with teachers, parents of prospective participants, and the students. This included approval

213 from a University Ethical Committee panel. The study was introduced and explained to the

214 teachers before data collection, and to the students at the beginning of a scheduled lesson.

215 Students were asked to answer a multi-section questionnaire honestly and were told that there

216 were no right or wrong answers. To maintain anonymity, student responses at different time

217 points were matched by a coding system using the students' date of birth and their class

218 identification. Students were asked to complete all measures near the end of primary school

219 (T1, in June or July), at the beginning of secondary school (T2, in November or December),

220 and around Easter vacation the following year (T3, in March or April). The participating

221 classes engaged in a range of activities over the course of the study, including soccer,

222 athletics, hockey, and basketball.

223 Measures 
Perceptions of teacher psychological need support. The instructional style of the

225

226

227

228

229

230

231

232

233

234

235

236

237

238

239

240

241

242

243

244

245

246

247

teacher was measured using 16 items from the Teacher As Social Context Questionnaire (TASCQ; Belmont, Skinner, Wellborn, \& Connell, 1992). Six items measured autonomy support (e.g., “My PE teacher listens to my ideas”), five items measured structure (e.g., “My PE teacher makes it clear what he/she expects of me”) and five items measured interpersonal involvement (e.g., “My PE teacher likes me”). All items were responded to on a 7-point scale ranging from 1 (not at all true) to 7 (very true) and the mean score of all items was taken to reflect overall need support. Internal consistency of the TASCQ has been demonstrated in a similar aged sample (Belmont et al., 1992).

Perceptions of peer-created task- and ego-climate. The extent to which peers were perceived to create a task- or ego-involved motivational climate was measured using nine items from the Peer Motivational Climate in Youth Sport Questionnaire (Ntoumanis, \& Vazou, 2005) adapted to physical education settings. The items followed the stem "In this PE class most pupils...” and were responded to on a 7-point scale ranging from 1 (not at all true) to 7 (very true). A task climate was measured using four items tapping into peers' emphasis on self-referenced improvement (e.g., "Help each other improve at activities and skills in PE”) and an ego climate was measured using five items assessing peers' emphasis on competition (e.g., "Want each other to perform better than other pupils in the class").

Factorial validity and internal consistency of the subscales have been demonstrated (Ntoumanis \& Vazou, 2005).

Motivational regulations. Motivational regulations were measured using the 20 items (four for each subscale) developed by Goudas, Biddle, and Fox (1994), which followed the stem, “I take part in PE. . . ” Example items are "Because it is exciting” (intrinsic motivation), "Because it is important for me to do well in PE” (identified regulation), “Because I would feel bad if I didn’t” (introjected regulation), “Because that's what I'm 
249 supposed to do" (external regulation), and "But I don’t really know why” (amotivation). All 250 items were responded to on a 7-point scale ranging from 1 (not at all true) to 7 (very true).

251 Factorial validity and internal consistency of the subscales has been recently demonstrated 252 (Lonsdale, Sabiston, Taylor, \& Ntoumanis, 2011). Physical self-concept. Physical self-concept was measured using the three items from the short form of the Physical Self-Description Questionnaire (Marsh, Martin, \& Jackson, 2010). An example item was "Physically, I am happy about myself” and items were responded to on a 6-point scale ranging from 1 (false) to 6 (true). Previous work has demonstrated the reliability and validity of the subscale (Marsh et al., 2010).

Physical activity. The Physical Activity Questionnaire for Older Children (PAQ-C;

259 Crocker, Bailey, Faulkner, Kowalski, \& McGrath, 1997) was used to assess participants’ 260 physical activity behavior. The PAQ-C measures 7-day recall of general levels of moderate and vigorous physical activity by utilizing memory cues, such as lunch time and evenings to enhance the recall of activity. An example item is, "In the last seven days, on how many evenings did you do sports, dance or play games in which you were very active?” Students then responded on a 5-point scale ranging from 1 (none) to 5 (6 or 7 last week, although this varied depending on the context of the question). Internal consistency and validity have been previously demonstrated in similar aged samples by Crocker et al. (1997).

\section{Data Analysis}

The data had a hierarchically nested structure with time points (level 1) nested within students (level 2), who were then nested within primary school classes (level 3). However,

270 some students from the same primary class moved to different secondary schools, therefore,

271 secondary school classes were not a higher level of analysis which encompassed primary

272 classes in an unambiguous fashion. Rather, students were cross-classified in primary school 273 classes and secondary school classes (i.e., a second level 3). As a result, we constructed 
274 cross-classified multilevel models (Hox, 2010) to carry out the analysis using MLwiN

275 software (version 2.25; Rasbash, Browne, Healy, Cameron, \& Charlton, 2012).

We first constructed intercept only models which allowed us to calculate the amount

277 of variance in each study variable associated with each level of analysis (i.e., within-person,

278 between-person, between-primary school class, and between-secondary school teacher). To

279 examine patterns of change in the study variables, unconditional growth models were created 280 by simultaneously adding a linear time predictor variable (each time point was dummy coded as 0,1 or 2) and a dichotomous school predictor variable indexing the transitional shift from primary to secondary school (coded as $0,1,1)$.

Next, we added the interpersonal variables as predictors of physical self-concept to the unconditional growth model. These variables were individual-mean centered to obtain a pure estimate of intraindividual effects (Enders \& Tofighi, 2007). The slope coefficients in this model represented the average relationship between the interpersonal variables and physical self-concept at the beginning of the study (i.e., in primary school; time $=0$ ). Therefore, we also included time $\times$ interpersonal variable interaction terms and school $\times$ interpersonal variable interaction terms. These terms examined whether the relationship between the interpersonal variable and physical self-concept a) changed over time and b) changed from primary to secondary school. As an estimate of effect size, $\mathrm{R}_{1}{ }^{2}$ values were calculated by comparing the final models to the intercept only models (i.e., the proportional reduction in error at the intraindividual level; Hox, 2010). interpersonal variables and then the analytical process was repeated with physical activity substituting physical self-concept as the outcome variable. 
Preliminary Analysis

Missing data was less than $0.01 \%$ of the total possible data. Such a low value is highly

301 unlikely to be problematic (Tabachnick \& Fidell, 2006); therefore, we imputed missing data

302 values using an expectation maximization algorithm to facilitate computation of the cross-

303 classified models. Means and bivariate correlations among the study variables can be found

304 in Table 1. The correlation between intrinsic motivation and identified regulation was very high; therefore, we took the conceptually and statistically defendable decision to calculate the mean of the two scores to create an 'autonomous motivation' variable. Table 2 shows the

Cronbach's alpha coefficients at each time point and the amount of variance in the study variables associated with each level of analysis. The Cronbach's alpha coefficients suggested that all scales demonstrated acceptable internal consistency. The intercept-only models indicated that most of the variance in the study variables was associated with the intraindividual level; however, a substantial level of variance was also associated with the interindividual level. Smaller amounts of variance in the study variables were associated with

313 the primary and secondary class levels; however, we retained these levels of analysis in our

314 multilevel models to remain faithful to the ecological structure of the data (Nezlek, 2008).

\section{Patterns of Changes in the Study Variables}

Results from the unconditional growth models can be seen in Table 3. Perceived need

317 support from the teacher and autonomous motivation towards PE generally decreased across

318 the course of the study, but a positive shift (i.e., an increase) occurred over the school

319 transition. Peer task-climate and physical self-concept also decreased linearly but no 320 transitional shift occurred. Physical activity also showed no linear change, but a significant negative shift (i.e., a decrease) from primary to secondary school was observed. No changes

322 were observed in peer ego-climate, introjected regulation, external regulation, and 323 amotivation. 


\section{Interpersonal Predictors of Physical Self-Concept and Physical Activity}

As shown in Table 4 (left side), perceptions of teachers’ need support positively predicted physical self-concept and the relationship was stable over time and school transition.

Neither facet of the peer environment predicted physical self-concept; however, peer taskclimate positively predicted self-reported physical activity. This relationship was constant over time and school transition. Need support from the teacher and peer ego-climate did not predict physical activity. Calculation of the $\mathrm{R}_{1}{ }^{2}$ values indicated that the models explained $6 \%$ and $14 \%$ of the intraindividual variance in physical self-concept and physical activity, respectively.

\section{Motivational Predictors of Physical Self-Concept and Physical Activity}

The results shown in Table 4 (right side) reveal that only autonomous motivation positively predicted physical self-concept, and the significant positive time $\times$ autonomous motivation term indicated that this relationship became stronger over the course of the study. Autonomous motivation also positively predicted physical activity, as did amotivation, and both of these relationships were stable over time and school. $\mathrm{R}_{1}{ }^{2}$ values indicated that the models explained $11 \%$ and $15 \%$ of the intraindividual variance in physical self-concept and physical activity, respectively. The positive relationship between amotivation and physical activity was contrary to theoretical postulates; therefore, to further explore this relationship we constructed a multilevel model with just amotivation entered as a predictor variable. The slope coefficient was small and not statistically significant $(b=.002, p=.912)^{1}$.

\section{Discussion}

Within the present study, we aimed to investigate the temporal patterns of children's physical self-concept, self-reported physical activity, motivation towards PE, and their perceptions of the motivational environment created by their peers and teachers over the transition from primary to secondary school. This is the first study to describe these trends by 
349 differentiating between linear patterns and abrupt transitional shifts. We also examined which 350 aspects of the motivational environment and specific motives for PE were important

351 correlates of children's physical self-concept and physical activity over this period and

352 whether these associations vary over time. Worryingly, some of the interpersonal and

353 motivational variables which are theorized to produce adaptive consequences declined over

354 the course of the study. Moreover, declines in children’s physical self-concept and self355 reported physical activity were also observed. These two important health outcomes were 356 associated with children’s changing perceptions of the PE environment and motivation 357 towards PE.

358 The general decline in perceived support for students' psychological needs may be 359 associated with children's changing needs during adolescence leading to different perceptions 360 concerning the quality of teacher-student relationships, in a similar manner to parent-child361 relationships (Collins \& Laursen, 2004). However, this broad decline coincided with an 362 incremental step-change in perceptions across the transition, which may be a consequence of 363 changes to actual teaching behavior from primary to secondary school teaching in the UK 364 (e.g., more emphasis on skill learning, specialist PE teachers). These distinct patterns 365 highlight the need for the nuanced analysis of change carried out in the present study. 366 Children's perceptions of the peer-created task environment and physical self-concept also 367 declined over the course of the study, yet the linear trend indicates that the school transition 368 per se may not be responsible for these changes but they may reflect more general 369 developmental challenges. The influential work of Nicholls (1989) proposed that at 370 approximately the age of 12-years old, children become capable of differentiating between 371 ability, effort and luck. This development may lead to shifting perceptions of the motivational 372 environment and sense of physical self during this period. 
From a motivational perspective, the transition from primary to secondary school was associated with a positive shift in autonomous motivation, which is in line with previous research proposing that the novelty of joining a new school may lead to enhanced motivation for some students (Delamont \& Galton, 1986). Nonetheless, this shift took place during developmental declines in autonomous motivation over the course of the study, which corresponds to similar trends in adolescence (Ntoumanis et al., 2009). Self-determination theorists propose that individuals hold a natural disposition to internalize and move towards self-determined action; however, as may be the case here, the social context has the potential to influence this process (Deci \& Ryan, 2000).

We found no evidence of the oft-cited developmental declines in PA (Brodersen et al., 2007); however, a negative transitional shift in self-reported physical activity was found in our sample. The transition from primary to secondary school may offer logistical and environmental opportunities to increase physical activity (e.g., active travel; Cooper et al., 2012). However, in the present sample these may not have been salient, or were perhaps overridden by interpersonal and individual factors that also influence the degree of physical activity (as well as physical self-concept) during childhood. Our subsequent analysis attempted to shed light on these factors.

Of the three interpersonal facets of the PE class motivational environment, we found that only the teacher was directly associated with physical self-concept and this association was equally important in primary and secondary school. From a self-determination theory perspective, psychological need supportive teaching provides children with clear guidelines and opportunities to demonstrate competence, allows them to feel connected and valued, and allows them to act volitionally (Taylor \& Ntoumanis, 2007). Measurements of autonomy support, which have also captured elements of structure and involvement, have been indirectly correlated to physical self-concept in secondary school pupils (Standage et al., 
2012). Our results build on this by implying that teachers have an important role to play in helping to stall general declines in physical self-concept in younger children. The novel intraindividual focus within the present study holds value for the future design of

interventions by showing that changes in children's perceptions of autonomy support,

402 structure and involvement from their typical levels may be associated with positive

403 developmental patterns in physical self-concept.

Variations in both task- and ego-involving aspects of the peer-created motivational environment did not predict physical self-concept. On reflection, however, neurocognitive evidence exists that peers may influence children’s sense of self to a greater degree following

407 pubertal changes to neural structures, as opposed to the early adolescence epoch measured in 408 the present study (Sebastian, Burnett, \& Blakemore, 2008). As a result, the findings offer 409 inadequate support for suggesting that interventions over the school transition focusing on peer-created motivational environments will be directly effective in shielding children’s

411 physical self-concept from commonly observed declines (as reported in the present study and

412 Marsh, 1989). Nonetheless, it would be premature to discount the effects of peers as

413 perceptions of the task-involved peer environment were associated with self-reported 414 physical activity. These findings imply that significant consideration of the specific outcome may be required in future intervention work, although the two outcomes are no doubt related.

416 If the protection of children's sense of self over the school transition is the aim, then peers

417 may not represent the best direct mechanism for achieving success and teaching practices

418 should be targeted. However, if children's physical activity behavior is the central focus, then 419 facilitating an environment where children emphasize effort, learning, and improvement may 420 have developmental worth. This latter point is corroborated by the body of evidence 421 concerning the central influence of peers on physical activity behavior (e.g., Finnerty, Reeves, 422 Dabinett, Jeanes, \& Vogele, 2010). 
In addition to interpersonal elements of the PE class transition, we also explored

motivational constructs grounded in SDT. Supporting our hypothesis, we found that

autonomous motives for PE (i.e., intrinsic and identified motives) were positively associated work (Standage et al., 2012), however, this relationship grew stronger over the course of the present study, implying that allowing students to function autonomously has greater consequences for self-concept as they age. Our findings also show that facilitating autonomous motives in PE may also be associated with enhanced self-reported physical activity (Taylor et al., 2010). Results from previous research imply that this can be achieved

432 by conducting teacher training interventions that focus on assisting teachers to provide a

433 psychological need satisfying environment (Cheon et al., 2012). associated with physical self-concept or physical activity was contrary to our hypothesis, however, null relationships among these controlling regulations and motivational

437 consequences have been observed at the intraindividual level in previous research (e.g.,

438 Taylor et al., 2010). What was more surprising and contrary to theoretical expectations was

439 the positive relationship between amotivation and physical activity. One possible explanation

440 for this finding is statistical suppression, whereby the inclusion of other variables in a

441 regression model increases the predictive utility of another variable (Conger, 1974). Our

442 supplementary analysis supported this possibility; however, we are reticent to rely solely on 443 this statistical justification for the unexpected finding. Alternatively, certain underlying 444 reasons for amotivation in PE may lead children to actively seeking out physical activity in 445 other contexts. For example, children who like physical activity but dislike the teacher and 446 their class mates may report high levels of amotivation within PE yet seek out physical 447 activity after school and at weekends (cf. Ntoumanis, Pensgaard, Martin, \& Pipe, 2004). 


\section{Overview and Limitations}

To summarize, children’s physical self-concept and self-reported physical activity

behavior were shown to decline in different ways over the period of a school transition. The

451 pattern of physical activity behavior, in particular, implicates the transition itself as a factor in

452 these declines. The school or class environment in secondary school may not be meeting the

453 needs of children as they develop (Meece et al., 2006), and not providing sufficient

opportunity for physical activity. This time in a child's life has important developmental

455

implications and should be a central focus in future research and applied practice. The present

study outlines interpersonal and motivational correlates that may be important in halting these

457 trends and, in general, these potential influences remain similar in magnitude across this

458 developmental transition period. Although these findings have important implications, the

459 study is not without its drawbacks. First, we relied on self-reports of children’s physical

460

activity behavior, therefore, future projects should attempt to use objective measures of

461

behavior. That said, self-report methods were deemed suitable as we focused on patterns of

462 physical activity behavior, rather than actual levels, and wished to obtain a relatively large

463 sample. Second, we could have considered many alternative aspects of the school

environment, as well as individual and environmental factors that potentially differ over the

school transition, such as the status of sport within the school, amount of homework,

cognitive maturation, and seasonal influences. We concentrated on the specific interpersonal

467 and motivational aspects in view of the theoretical support which suggested they may help

468 explain temporal changes; however, scholars may wish to consider alternative correlates in

469 combination with these psychological factors in future work. From a theoretical perspective,

470 scholars may wish to replicate or rebut the positive intraindividual association observed

471 between amotivation in PE and physical activity. For example, if children experience

472 increased absence of motivation in PE, do they seek out other opportunities for physical 
473 activity? Bidirectional influences may also be recognized in future work, whereby physical

474 self-concept and physical activity behavior may influence children’s motivation and

475 perceptions of the environment in PE classes. Recognition that the psychological needs

476 support provided by the teacher may influence the motivational environment created by peers

477 may also be beneficial. Finally, it is worth noting the high correlations between the intrinsic

478 and identified motives, which led us to combine the two motivation regulations. This problem

479 has been noted previously (Lonsdale et al., 2011), hence, subsequent psychometric and

480 conceptual research on improving the distinguishability of the two types of motivation may

481 be commendable.

482 To conclude, the present study highlights several interpersonal and motivational

483 factors that have important implications for the psychological and physical development of

484 children over the period of a school transition. These factors should, therefore, be a target of

485 future intervention to prevent the observed declines in physical self-concept and physical

486 activity behavior. 


\section{Footnote}

$488{ }^{1}$ A reviewer recommended that we considered gender in all analyses, however, very few 489 differences were observed when doing so. Girls reported a greater linear decline in

490 psychological need support from the teacher and a greater negative shift across the transition 491 in peer ego-climate. No differences in substantive conclusions were found (and also very 492 little difference in the statistical parameters) in interpersonal and motivational predictors of 493 self-concept and physical activity.

494

495

496

497

498

499

500

501

502

503

504

505

506

507

508

509

510

511 


\section{References}

513 Barkoukis, V., Ntoumanis, N., \& Thøgersen-Ntoumani, C. (2010). Developmental changes in achievement motivation and affect in physical education: growth trajectories and demographic differences. Psychology of Sport and Exercise, 11, 83-90. doi: http://dx.doi.org/10.1016/j.psychsport.2009.04.008

517 Belmont, M., Skinner, E., Wellborn, J., \& Connell, J. (1992). Teacher as social context: A measure of student perceptions of teacher provision of involvement, structure and autonomy support. Rochester, NY: University of Rochester.

520 British Heart Foundation (2009). Couch kids: The nation's future. London: British Heart Foundation.

522 Brodersen, N. H., Steptoe, A., Boniface, D. R., \& Wardle, J. (2007). Trends in physical

523

524

525

526

527

528

529

530

531

532

533

534

535 activity and sedentary behaviour in adolescence: Ethnic and socioeconomic differences. British Journal of Sports Medicine, 41, 140-144. doi:

\section{http://dx.doi.org/10.1136/bjsm.2006.031138}

Centers for Disease Control and Prevention (2011). School health guidelines to promote healthy eating and physical activity. Morbidity and Mortality Weekly Report. Recommendations and Reports. U.S. Department of Health and Human Services.

Cheon, S. H., Reeve, J., \& Moon, I. S. (2012). Experimentally-based, longitudinallydesigned, teacher-designed, teacher-focused intervention to help physical education teachers be more autonomy supportive. Journal of Sport \& Exercise Psychology, 34, 365-396.

Collins, W. A., \& Laursen, B. (2004). Parent-adolescent relationships and influences. In R. M. Lerner \& L. Steinberg (Eds.), Handbook of adolescent psychology (2nd ed., pp. 331-361). Hoboken, NJ: Wiley. 
536 Conger, A. J. (1974) A revised definition for suppressor variables: A guide to their identification and interpretation. Educational Psychological Measurement, 34, 35-46. doi:10.1177/001316447403400105

539 Connell, J. P., \& Wellborn, J. G. (1991). Competence, autonomy, and relatedness: A motivational analysis of self-system processes. Minnesota Symposia on Child $541 \quad$ Psychology, 23, 43-77.

542 Cooper, A. R., Jago, R. P., Southward, E. F., \& Page, A. S. (2012). Active travel and physical activity across the school transition: The PEACH project. Medicine and Science in Sports and Exercise, 44, 1890-1897. doi: http://dx.doi.org/10.1249/MSS.0b013e31825a3a1e.

546 Crocker, P. R., Bailey, D. A., Faulkner, R. A., Kowalski, K. C., \& McGrath, R. (1997). Measuring general levels of physical activity: Preliminary evidence for the physical activity questionnaire for older children. Medicine and Science in Sports \& Exercise, 29, 1344-1349. doi:10.1097/00005768-199710000-00011

550 Crocker, P. R. E., Sabiston, C. M., Kowalski, K. C., McDonough, M. H., \& Kowalski, N. (2006). Longitudinal assessment of the relationship between physical self-concept and health-related behavior and emotion in adolescent girls. Journal of Applied Sport Psychology, 18, 185-200. doi: 10.1080/10413200600830257

554 Deci, E. L., \& Ryan, R. M. (2000). The “what” and “why” of goal pursuits: Human needs 555 and the self-determination of behavior. Psychological Inquiry, 11, 227-268. doi:10.1207/S15327965PLI1104_01

557 Delamont, S., \& Galton, M. (1986) Inside the secondary classroom. London: Routledge \& 558 Kegan Paul. 
559 Eccles, J. S., \& Roeser, R. W. (2011). Schools as developmental contexts during adolescence.

560

561

562

563

564

565

566

567

568

569

570

571

572

573

574

575

576

577

578

579

580

581

582

583 Journal of Research on Adolescence, 21, 225-241. doi: 10.1111/j.15327795.2010.00725.x

Enders, C. K., \& Tofighi, D. (2007). Centering predictor variables in cross-sectional multilevel models: A new look at an old issue. Psychological Methods, 12, 121-138. doi:10.1037/1082-989X.12.2.121

Finnerty, T., Reeves, S., Dabinett, J., Jeanes, Y., \& Vogele, C. (2010). Effects of peer influence on dietary intake and physical activity in school children. Public Health Nutrition Journal, 13, 376 - 383. doi: http://dx.doi.org/10.1017/S1368980009991315

Fox, K. R. (1992). Physical education and the development of self-esteem in children. In N. Armstrong (Ed.), New directions in physical education: Towards a national curriculum (Vol. 2, pp. 33-54). Champaign, IL: Human Kinetics.

Garcia, A., Pender, N., Antonakos, C., \& Ronis, D. (1998). Changes in physical activity beliefs and behaviors of boys and girls across the transition to junior high school. Journal of Adolescent Health, 22, 394-402. doi: http://dx.doi.org/10.1016/S1054139X(97)00259-0

Gillison, F., Osborn, M., Skevington, S., \& Standage, M. (2009). Exploring the experience of introjected regulation for exercise across gender in adolescence. Psychology of Sport \& Exercise, 10, 309-319. doi: http://dx.doi.org/10.1016/j.psychsport.2008.10.004

Goudas, M., Biddle, S., \& Fox, K. (1994). Perceived locus of causality, goal orientations, and perceived competence in school physical education classes. The British Journal of Educational Psychology, 64, 453 - 463. doi:10.1111/j.2044-8279.1994.tb01116.x

Horn, T. S., \& Amorose, A. J. (1998). Sources of competence information. In J.L. Duda (Ed.) Advances in sport and exercise psychology measurement (pp.49-63). Morgantown, WV: Fitness Information Technology. 
584 Hox, J. J. (2010). Multilevel analysis. Techniques and applications. 2nd Edition. New York:

$585 \quad$ Routledge.

586 Jõesaar, H., Hein, V., \& Hagger, M. S. (2012). Youth athletes’ perception of autonomy

587 support from the coach, peer motivational climate and intrinsic motivation in sport

588 setting: One-year effects. Psychology of Sport and Exercise, 13, 257-262. doi:

$589 \quad$ 10.1016/j.psychsport.2011.12.001

590 Lonsdale, C., Sabiston, C. M., Taylor, I. M., \& Ntoumanis, N. (2011). Measuring student 591 motivation for physical education: Examining the psychometric properties of the 592 perceived locus of causality questionnaire and the situational motivation scale.

$593 \quad$ Psychology of Sport \& Exercise, 12, 284-292. doi:10.1016/j.psychsport.2010.11.003

594 Marsh, H. W. (1989). Age and sex effects in multiple dimensions of self-concept:

595 Preadolescence to early adulthood. Journal of Educational Psychology, 81, 417-430.

596 doi: $10.1037 / 0022-0663.81 .3 .417$

597 Marsh, H. W. (2007). Physical self-concept and sport. In S. Jowett \& D. Lavallee (Eds.), $598 \quad$ Social psychology in sport (pp. 159-179). Champaign, IL: Human Kinetics.

599 Marsh, H. W., Martin, A. J., \& Jackson, S. (2010). Introducing a short version of the Physical 600 Self Description Questionnaire: New strategies, short-form evaluative criteria, and 601 applications of factor analyses. Journal of Sport \& Exercise Psychology, 32, 438-482.

602 Meece, J., Anderman E. M., \& Anderman, L. H. (2006).Classroom goal structure, student 603 motivation, and academic achievement. Annual Review of Psychology, 57, 505-528.

605 Nezlek, J. B. (2008). An introduction to multilevel modeling for social and personality 606 psychology. Social and Personality Psychology Compass, 2, 842-860. doi:10.1111/j.1751-9004.2007.00059.x 
608 Nicholls, J. (1989). The competitive ethos and democratic education. Cambridge, MA:

$609 \quad$ Harvard University Press.

610 Ntoumanis, N., Barkoukis, V., \& Thøgersen-Ntoumani, C. (2009). Developmental

611 trajectories of motivation in physical education: course, demographic differences and 612 antecedents. Journal of Educational Psychology, 101, 717-728. doi:

\section{$613 \quad$ http://dx.doi.org/10.1037/a0014696}

614 Ntoumanis, N., \& Biddle, S. J. H. (1999). A review of motivational climate in physical activity. Journal of Sport Sciences, 17, 643-665. doi:10.1080/026404199365678

616 Ntoumanis, N., Pensgaard, A.M., Martin, C., \& Pipe, K. (2004). An ideographic analysis of amotivation in compulsory school physical education. Journal of Sport and Exercise Psychology, 26, 197-214.

619 Ntoumanis, N., \& Vazou, S. (2005). Peer motivational climate in youth sport: Measurement 620 development. Journal of Sport \& Exercise Psychology, 27, 432-455.

621 Ntoumanis, N. Taylor, I. M., \& Thøgersen-Ntoumani, C. (2012). A longitudinal examination of coach and peer motivational climates in youth sport: Implications for moral attitudes, well-being, and behavioral investment. Developmental Psychology. 48, 213223. doi: $10.1037 / \mathrm{a} 0024934$.

Rasbash, J., Browne, W.J., Healy, M., Cameron, B., \& Charlton, C. M. J. (2012). MLwiN 626 Version 2.25.

627 Sebastian, C., Burnett, S., \& Blakemore, S-J. (2008). Development of the self-concept during 628 adolescence. Trends in Cognitive Science, 12, 441-446.

630 doi:10.1016/j.tics.2008.07.008

Spray, C. M., Warburton, V. E., \& Stebbings, J. (2013). Change in physical self-perceptions across the transition to secondary school: Relationships with perceived teacher- 
emphasised achievement goals in physical education. Psychology of Sport and Exercise, 14, 662-669. doi: http://dx.doi.org/10.1016/j.psychsport.2013.05.001

Standage, M., Duda, J. L., \& Ntoumanis, N. (2003). A model of contextual motivation in physical education: Using constructs from self-determination and achievement goal theories to predict physical activity intentions. Journal of Educational Psychology, 95, 97 - 110. doi:10.1037//0022-0663.95.1.97

Standage, M., Gillison, F. B., Ntoumanis, N., \& Treasure, G. C. (2012). Predicting students' physical activity and health-related well-being: A prospective cross-domain investigation of motivation across school physical education and exercise settings. Journal of Sport \& Exercise Psychology, 34, 37-60.

Stensel, D. J., Gorely, T., \& Biddle, S. J. H. (2008). Youth health outcomes. In A. L. Smith \& S. J. H. Biddle (Eds). Youth physical activity and sedentary behavior. Challenges and solutions (pp. 31-57). Champaign, IL: Human Kinetics.

Tabachnick, B. G., \& Fidell, L. S. (2006). Using multivariate statistics, 5th ed. Boston: Allyn and Bacon.

Taylor, I. M., \& Ntoumanis, N. (2007). Teacher motivational strategies and student selfdetermination in physical education. Journal of Educational Psychology, 99, 747-760. doi:10.1037/0022-0663.99.4.747

Taylor, I. M., Ntoumanis, N., Standage, M., \& Spray, C. M. (2010). Motivational predictors of physical educational students' effort, exercise intentions, and leisure-time physical activity: A multilevel linear growth analysis. Journal of Sport \& Exercise Psychology, 32, 99 - 120.

Verloigne, M., Van Lippevelde, W., Maes, L., Yildirim, M., Chinapaw, M., Manios, Y., et al. (2012). Levels of physical activity and sedentary time among 10- to 12-year-old boys and girls across 5 European countries using accelerometers: an observational study 
657

658

659

660

661

662

663

664 within the ENERGY-project. International Journal of Behavioral Nutrition and Physical Activity, 9, 34. doi: 10.1186/1479-5868-9-34

Warburton, V. E., \& Spray, C. (2008). Motivation in physical education across the primarysecondary school transition. European Physical Education Review, 14, 157-178. doi: 10.1177/1356336X08090704

Wigfield, A., Eccles, J. S., \& Pintrich, P. R. (1996). Development between the ages of 11 and 25. In D. C. Berliner \& R. C. Calfee (Eds.), Handbook of Educational Psychology (pp. 148-185). New York: Macmillan. 
665Table 1

666Means, Standard Deviations and Bivariate Correlations of all Study Variables at the Beginning of the Study (i.e., Time 1).

\begin{tabular}{|c|c|c|c|c|c|c|c|c|c|c|c|c|}
\hline \multirow[b]{2}{*}{ Variable } & \multicolumn{3}{|c|}{ Mean (SD) } & \multicolumn{9}{|c|}{ Bivariate Correlations } \\
\hline & Time 1 & Time 2 & Time 3 & 1. & 2. & 3. & 4. & 5. & 6. & 7. & 8. & 9. \\
\hline 1. Psych. Need Support & $5.07(1.09)$ & $5.04(0.97)$ & $4.77(1.12)$ & - & & & & & & & & \\
\hline 2. Peer Task Climate & $4.92(1.10)$ & $4.77(1.10)$ & $4.50(1.13)$ & $.42 * *$ & - & & & & & & & \\
\hline 3. Peer Ego Climate & $4.88(0.93)$ & $4.88(0.94)$ & $4.88(0.98)$ & $.27 * *$ & .02 & - & & & & & & \\
\hline 4. Intrinsic Motivation & $5.33(1.42)$ & $5.45(1.39)$ & $5.13(1.49)$ & $.54 * *$ & $.39 * *$ & $.19 * *$ & - & & & & & \\
\hline 5. Identified Regulation & $5.52(1.30)$ & $5.61(1.21)$ & $5.34(1.38)$ & $.53 * *$ & $.40^{* *}$ & $.19 * *$ & $.81^{* *}$ & - & & & & \\
\hline 6. Introjected Regulation & 3.99(1.45) & $4.10(1.40)$ & $4.00(1.44)$ & $.25^{* *}$ & $.20 * *$ & $.23 * *$ & $.33 * *$ & $.37 * *$ & - & & & \\
\hline 7. External Regulation & $3.81(1.63)$ & $3.65(1.69)$ & $3.68(1.70)$ & $-.18 * *$ & $-.11^{* *}$ & .04 & $-.30 * *$ & $-.19 * *$ & $.33 * *$ & - & & \\
\hline 8. Amotivation & $2.21(1.34)$ & $2.17(1.36)$ & $2.27(1.42)$ & $-.25 * *$ & $-.19 * *$ & .01 & $-.46 * *$ & $-.47 * *$ & $.11^{*}$ & $.42 * *$ & - & \\
\hline 9. Physical Self-Concept & $4.96(1.11)$ & $4.86(1.15)$ & $4.69(1.27)$ & $.31^{* *}$ & $.18^{* *}$ & .05 & $.44^{* *}$ & $.36^{* *}$ & $.15^{* *}$ & .07 & $-.16^{* *}$ & - \\
\hline 10. Physical Activity & $3.46(0.76)$ & $3.09(0.74)$ & $3.14(0.80)$ & $.16^{* *}$ & $.14^{* *}$ & $.10^{*}$ & $.31^{* *}$ & $.33^{* *}$ & $.15^{* *}$ & $-.11^{*}$ & $-.17 * *$ & $.20 * *$ \\
\hline
\end{tabular}

$66 \overline{\mathbb{N} \text { ote. }}{ }^{*} p<.05, * * p<.01$. All scales were responded to on a 1-7 scale with the exceptions of physical self-concept (1-6) and physical activity (1-5). 
Table 2

669 Cronbach's Alpha Coefficients and Variance Associated with Each Level of Analysis for All Study Variables

\begin{tabular}{|c|c|c|c|c|c|c|c|}
\hline & \multicolumn{3}{|c|}{ Cronbach’s Alpha } & \multicolumn{4}{|c|}{ Variance } \\
\hline & Time 1 & Time 2 & Time 3 & Level 1 & Level 2 & $\begin{array}{l}\text { Level } 3 \\
\text { primary }\end{array}$ & $\begin{array}{c}\text { Level } 3 \\
\text { secondary }\end{array}$ \\
\hline Psych. Need Support & .92 & .92 & .94 & $0.68^{*}$ & $0.35 *$ & $0.06 *$ & $0.06 *$ \\
\hline Peer Task-Climate & .73 & .80 & .81 & $0.78^{*}$ & $0.38 *$ & $0.09 *$ & 0.03 \\
\hline Peer Ego Climate & .68 & .76 & .76 & $0.58 *$ & $0.26^{*}$ & 0.02 & $0.04 *$ \\
\hline Autonomous Motivation & .91 & .91 & .93 & $0.76^{*}$ & $0.78^{*}$ & 0.06 & $0.09 *$ \\
\hline Introjected Regulation & .71 & .71 & .73 & $1.05 *$ & $0.91 *$ & 0.07 & 0.01 \\
\hline External Regulation & .77 & .83 & .85 & $1.47^{*}$ & $1.25 *$ & 0.07 & 0.02 \\
\hline Amotivation & .77 & .82 & .82 & $1.00^{*}$ & $0.80^{*}$ & 0.05 & 0.05 \\
\hline Physical Self-concept & .86 & .91 & .94 & $0.65 *$ & $0.69 *$ & 0.00 & $0.06^{*}$ \\
\hline Physical Activity & .75 & .76 & .81 & $0.35 *$ & $0.22 *$ & 0.02 & $0.03 *$ \\
\hline
\end{tabular}

$670 \quad$ Note. $* p<.05$ 
PHYSICAL EDUCATION DURING SCHOOL TRANSITION 30

671 Table 3

672 Regression Coefficients Describing Change in Study Variables across Time and School

\begin{tabular}{lccc}
\hline Variable & Intercept & Linear Time & School Transition \\
\hline Psychological Need Support & 5.07 & $-.28^{* * *}$ & $.26^{* *}$ \\
Peer Created Task-Climate & 4.92 & $-.27^{* * *}$ & .12 \\
Peer Created Ego-Climate & 4.87 & -.02 & .02 \\
Autonomous Motivation & 5.47 & $-.30^{* * *}$ & $.41^{* * *}$ \\
Introjected Regulation & 4.03 & -.10 & .21 \\
External Regulation & 3.81 & .04 & -.21 \\
Amotivation & 2.22 & .09 & -.14 \\
Physical Self-Concept & 4.94 & $-.17^{* * *}$ & .08 \\
Physical Activity & 3.46 & .05 & $-.43^{* * *}$ \\
\hline
\end{tabular}

673 Note. $* p<.05, * * p<.01, * * * p<.001$

674

675

676

677

678

679

680

681

682

683

684

685 
686

687 Multilevel Models Exploring Motivational (left side) and Interpersonal (right side) Predictors

688 of Physical Self-Concept and Physical Activity

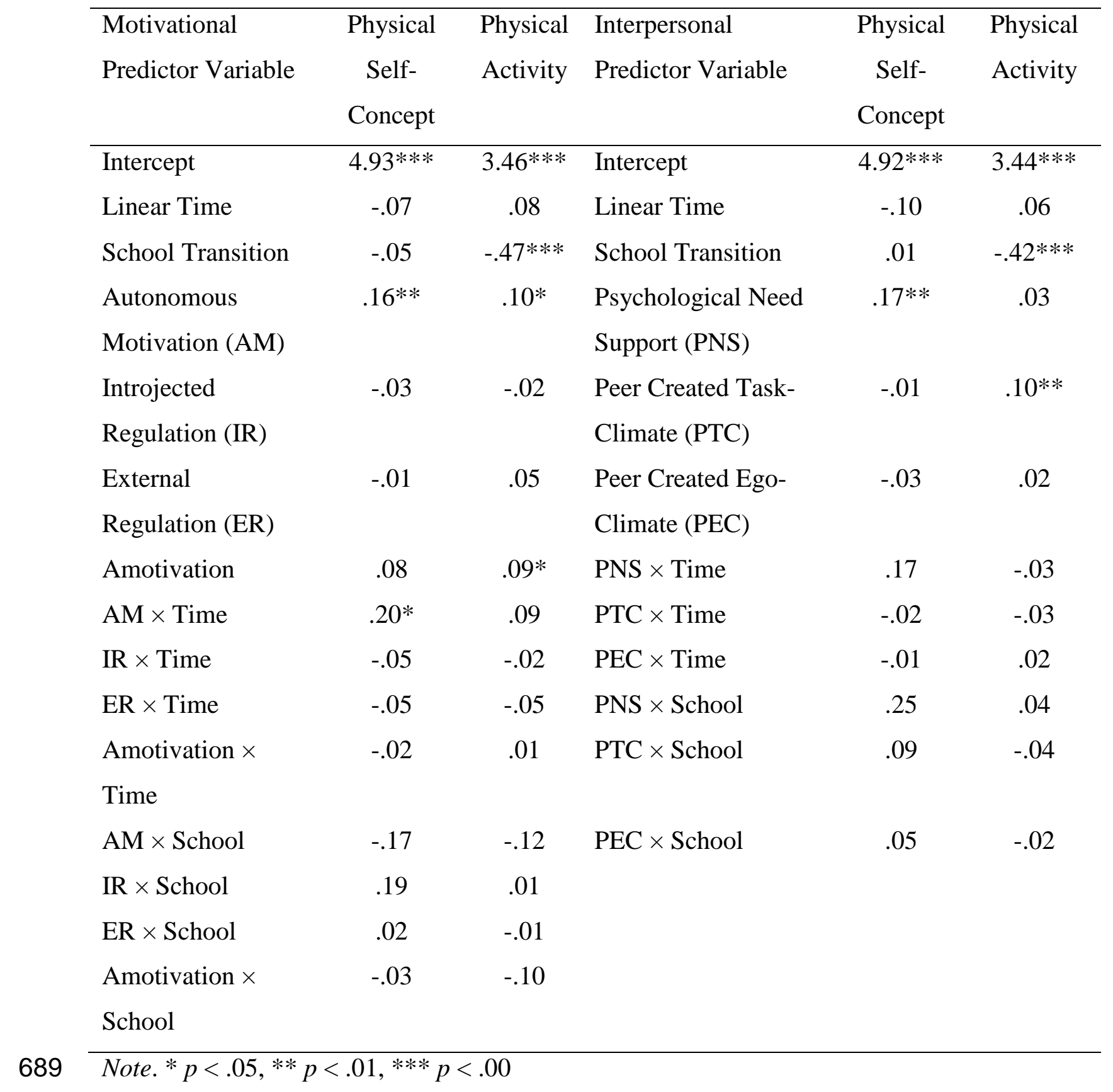

Table 4 